\title{
Migration routes, population status and important sites used by the globally threatened Black-faced Spoonbill (Platalea minor): a synthesis of surveys and tracking studies
}

Yiwen Chen ${ }^{1,2+}$, Yat-tung Yü ${ }^{3 \dagger}$, Fanjuan Meng ${ }^{2,4}$, Xueqin Deng ${ }^{2,4}$, Lei Cao ${ }^{2,4^{*}}$ and Anthony David Fox ${ }^{5}$

\begin{abstract}
Background: The Black-faced Spoonbill (Platalea minor) is a globally threatened species, nesting mainly in western Korea with smaller numbers breeding in Liaoning Province, China, and Far East Russia. Recent winter field surveys to estimate the species' population size were almost totally conducted in coastal areas, but tracking studies showed that some individuals now winter inland. To ensure its long-term survival, we need a more comprehensive assessment of the current distribution and abundance of the species.

Methods: We combined the most recent count data and satellite tracking information to update existing information about the population abundance and distribution of the Black-faced Spoonbill at all stages of its annual life cycle, and how these have changed during 2004-2020.

Results: Black-faced Spoonbills mainly breed on the west coast of the Korean peninsula, while immature birds show a wider summer distribution throughout Yellow Sea coastal areas, when a few remain on wintering sites in the south. Combined tracking results and mid-winter counts confirmed known wintering sites on the east and south coasts of China, but showed that the species also winters on wetlands in the Yangtze River floodplain and in Southeast Asia. During 2004-2020, counts of wintering birds in coastal habitats increased from 1198 to 4864, with numbers wintering on the island of Taiwan contributing most to the overall increase. Latest counts found 5222 in 2021 . We also identify key wintering and stopover sites as well as their current conservation status.

Conclusions: This study revised the known summering and wintering ranges of the Black-faced Spoonbill and assessed the conservation status of key sites based on a combination of field survey and satellite tracking data. We recommend prioritisation of further field research to identify and survey inland wintering areas in the Yangtze River floodplain and summering areas of immature birds. More tracking of adult individuals and birds during spring migration is necessary to fill these information gaps. We also suggest establishing a Black-faced Spoonbill monitoring platform to store, share and show real-time distribution range and population abundance data.
\end{abstract}

\footnotetext{
*Correspondence: leicao@rcees.ac.cn

${ }^{\dagger}$ Yiwen Chen and Yat-tung Yu are co-first authors

${ }^{2}$ State Key Laboratory of Urban and Regional Ecology, Research

Center for Eco-Environmental Sciences, Chinese Academy of Sciences,

Beijing 100085, China

Full list of author information is available at the end of the article
}

(c) The Author(s) 2021. Open Access This article is licensed under a Creative Commons Attribution 4.0 International License, which permits use, sharing, adaptation, distribution and reproduction in any medium or format, as long as you give appropriate credit to the original author(s) and the source, provide a link to the Creative Commons licence, and indicate if changes were made. The images or other third party material in this article are included in the article's Creative Commons licence, unless indicated otherwise in a credit line to the material. If material is not included in the article's Creative Commons licence and your intended use is not permitted by statutory regulation or exceeds the permitted use, you will need to obtain permission directly from the copyright holder. To view a copy of this licence, visit http://creativecommons.org/licenses/by/4.0/. The Creative Commons Public Domain Dedication waiver (http://creativeco mmons.org/publicdomain/zero/1.0/) applies to the data made available in this article, unless otherwise stated in a credit line to the data. 
Keywords: Black-faced Spoonbill, Breeding distribution, Coastal mudflats, Conservation status, Platalea minor, Population abundance, Winter distribution, Yangtze River floodplain

\section{Background}

The Black-faced Spoonbill (Platalea minor) is a globally threatened waterbird, which breeds mainly on the west coast of the Korean Peninsula (Kang et al. 2016), with small numbers breeding in Liaoning Province, China (Ding et al. 2000) and Far East Russia (Shibaev 2010). It winters in coastal areas of south and southeast Chinese mainland, on Taiwan and Hainan in China, western Japan, and Southeast Asia (BirdLife International and Handbook of the Birds of the World 2019), constituting just one biogeographical population (Wetlands International 2020).

Black-faced Spoonbills were considered relatively common prior to the 1950s, but the population declined during the Korean War, because of the destruction of breeding sites and subsequent pollution of habitats, thought to be caused by pesticide use (Yeung et al. 2006). In 1980s, the global population numbered less than 300 individuals (Kennerley 1989), and the species was designated as "Critically Endangered" by International Union for Conservation of Nature (IUCN) in 1994 (BirdLife International and Handbook of the Birds of the World 2017). Conservation efforts, including considerable investment in site protection during 1997-2014, increased the population of Black-faced Spoonbills from 535 to 2726 individuals (Sung et al. 2018), and the threatened category was down-listed to "Endangered" in 2000 (BirdLife International and Handbook of the Birds of the World 2017). During the 2021 global synchronous census coordinated by the Hong Kong Bird Watching Society (HKBWS), the number of wintering Black-faced Spoonbills reached a new maximum of 5222 individuals (Yu et al. 2021).

Besides the census, the first satellite tracking research was also initiated in 1998 in order to locate previously undiscovered breeding grounds, migration routes and stopover sites (Ueta et al. 2002) and further studies were undertaken in the 2010s (Wood et al. 2013; Jung et al. 2018; Jia et al. 2020; Son et al. 2020). Results from these latter studies revealed that immature individuals could remain on inland habitats during winter, indicating that the midwinter count focusing almost entirely on coastal areas could miss some individuals wintering inland.

Black-faced Spoonbills are sensitive to human disturbance (Ding et al. 2000; Zhang et al. 2010), while climate change and habitat loss together also threaten the recovery of the population (Pickett et al. 2018). Although recent studies have revealed valuable information about population size and trends, distribution, and the migration routes of the Black-faced Spoonbills, we still need more knowledge relating to the important sites used by the species throughout the annual cycle and their conservation status. It is especially important for us to (1) understand the distribution of the Black-faced Spoonbill throughout the annual cycle, and (2) confirm whether current levels of site protection are adequate to secure the population for the future. Here, we attempt to provide new information in the current analysis to fulfil these two objectives.

\section{Methods \\ Information sources \\ Count data}

We derived census information from recent waterbird field surveys and from published information to establish the full distributional range and abundance of the Blackfaced Spoonbill at different points in its annual cycle. The information included figures from the synchronized surveys conducted by the Hong Kong Bird Watching Society (HKBWS) during 2004-2020 (Sung et al. 2018; Yu et al. 2020), synchronized Yangtze waterbird surveys in 2004, 2005, 2016, 2018, 2019 and 2020 (Cao et al. 2010), and records in published scientific papers. The synchronized HKBWS surveys presented only count figures from major wintering sites (which are known to comprise at least $90 \%$ of the total numbers recorded during the census) from 2004 to 2020. Synchronized Yangtze waterbird surveys were undertaken during mid-January to early February, which are considered to cover the majority of the possible wintering sites of Black-faced Spoonbills in inland China (Yu and Swennen 2005; Cao et al. 2010). Other field survey results and satellite tracking results were obtained from published articles by searching the internet (www.cnki.net; apps.webofknowledge.com; scihub.org.cn) with key words ("black-faced spoonbill" or "black-faced spoonbills" or "Platalea minor") (Additional file 1: Table S1).

\section{Telemetry data}

Telemetry data analyzed and presented here from all available studies derive from 34 different tagged individuals. These include 24 complete autumn migration routes from 24 birds caught at Chinese and South Korean breeding sites and 10 complete spring migration routes from 10 birds caught at two key wintering sites on Taiwan and Hong Kong in China (see Additional file 1: Table S2 for 
detail information on individuals and Additional file 1: Table S3 for data summaries from tracking studies).

\section{Analysis}

We created new distribution maps based on the information from recent field surveys and tracking studies, overlaying these upon the distribution map generated by BirdLife International and Handbook of the Birds of the World (2019) within an ArcGIS 10.6 environment.

We used the telemetry results and data from field surveys on the wintering areas (Jin et al. 2009), breeding areas (Lee et al. 2001; Kang et al. 2016) and stopover areas (Yuan and Zhang 2006) to define different periods of the annual cycle (see "Results" below). Based on the information from the literature, we assigned birds using sites during the defined wintering period (DecemberFebruary, see "Results" below) to wintering sites. Breeding sites were defined based upon direct observation of birds' breeding behavior or movements to and from colonies interpreted from tracking data. Other sites occupied by birds during the period defined as summer (between May and September; see "Results" below), in the absence of evidence of breeding were noted as summering sites. We also present a tentative map of possible migration routes based on the combined results from the telemetry studies.

We attempted to assess the total current population size and the trends in abundance within some larger geographical units in recent years based on the HKBWS's synchronized survey results from mid-winter counts carried out during 2004-2020, and supplemented by additional information from other sources. Population abundance and trends were analyzed by grouping individual sites as follows: Yangtze River Delta (including Shanghai, Zhejiang, and Jiangsu Province), Fujian Coast, Pearl River Delta (including Hong Kong, Macau and Guangdong Province), Hainan, on the island of Taiwan and in Japan, Korea, Philippines, Thailand and Red River Delta of Vietnam.

Internationally important wintering sites were determined based on the average of total winter counts from 2016 to 2020 (the past 5 years, according to the Ramsar criterion; Ramsar 2007), for identifying important key sites (defined as supporting $>5 \%$ of the population) and regular key sites ( $>1 \%$ of the population; Damba et al. 2020). We arbitrarily defined key stopover sites as those used by more than $0.25 \%$ of the total wintering counts or that supported staging tagged individuals for more than 7 days. In five cases [two reported by Liu (2006) and three reported by Son et al. (2020)], it was not clear precisely how long birds had remained at stopover sites, so these were estimated in Table 1. To assess the current protection status of these key sites based on the definitions above, we downloaded the boundary information from the World Database of Protected Areas (WDPA, https:// www.protectedplanet.net/en/thematic-areas/wdpa) and National Nature Reserves (NNRs, http://www.resdc.cn/ data.aspx?DATAID =272) with permissions. We then overlaid all the key wintering sites using ArcGIS 10.6 to identify which sites were located within WDPA and NNR boundaries. However, during this process we also became aware that the boundary information held in WDPA did not reflect the true protected area boundaries in a very few cases. For this reason, we asked the opinion of local experts to define the precise geographical extent of protection status for a few sites, e.g., the Deep Bay area of Hong Kong.

\section{Results}

\section{Distribution}

From the results presented here, we can add a breeding site in South Korea (Chilsando Islet; Kang et al. 2016) revealed by field surveys, and summering sites revealed by telemetry tracking, including Yancheng NNR in Jiangsu Province, China (Ueta et al. 2002). These results confirm that all the known summering sites are exclusively coastal and restricted to South Korea, China, and Russia (Fig. 1).

Tracking results from 11 individuals showed birds wintering in other previously less known areas. These include: Yancheng NNR in Jiangsu Province (Jia et al. 2020); Hangzhou Bay and Taizhou Bay in Zhejiang Province (Jung et al. 2018); Yangtze River floodplain [Poyang Lake in Jiangxi Province and Nanyi Lake in Anhui Province (Jia et al. 2020), Yongzhou in Hunan Province (Son et al. 2020), Wang Lake in Hubei Province (Wood et al. 2013), Shijiu Lake in Jiangsu Province (Jung et al. 2018)]; Funing Bay of Fujian Coast (Son et al. 2020) and Luoyuan Bay and Xiamen (Jung et al. 2018), all in Fujian Province; and Tra-sur Flooded Forest on the border of Vietnam and Cambodia (Wood et al. 2013). Based on HKBWS field survey results, Black-faced Spoonbills also winter on Batanes Island and Panpang in Philippines and Phetchaburi in Thailand (Yu et al. 2020). With the exception of the inland freshwater Yangtze River floodplain and the Tra-sur Flooded Forest, all other wintering areas are maritime coastal East Asian habitats (Fig. 1).

The results suggest the inclusion of the south coast of South Korea and the coastal area east to the Han River in South Korea (Kim and Kim 2005) as part of the staging areas, as well as parts of Shandong Province (Yellow River Delta; Shan et al. 2005) and Zhejiang Province (Hangzhou Bay; Jin et al. 2017) in China. Telemetry tracking data also revealed stopover sites on the southeast coast of Shandong Province (Rongcheng and Jiaozhou Bay; Jia et al. 2020) and Jiangsu Province (Linhong Esturay; Jia 
Table 1 Migration schedules from 34 tracked Black-faced Spoonbills (Platalea minor)

\begin{tabular}{|c|c|c|c|c|c|c|}
\hline ID & Summering site & Departure time & Wintering site & Arriving time & $\begin{array}{l}\text { Duration } \\
\text { (days) }\end{array}$ & Resource \\
\hline 1 & Chilsando Islet, South Korea & $2014 / 11 / 3$ & Hangzhou Bay, Yangtze River Delta & $2014 / 11 / 6^{*}$ & $3^{*}$ & Jung et al. (2018) \\
\hline 2 & Chilsando Islet, South Korea & 2017/10/13 & Yongzhou, Hunan & 2017/10/15 & 2 & Son et al. (2020) \\
\hline 3 & Chilsando Islet, South Korea & 2017/10/30 & Funing Bay, Fujian Coast & $2017 / 11 / 1$ & 2 & Son et al. (2020) \\
\hline 4 & Chilsando Islet, South Korea & 2014/11/4 & Xiamen, Fujian Coast & $2014 / 11 / 12^{*}$ & $8^{*}$ & Jung et al. (2018) \\
\hline 5 & Chilsando Islet, South Korea & 2017/10/28 & Hong Kong, Pearl River Delta & 2017/11/2 & 5 & Son et al. (2020) \\
\hline 6 & Chilsando Islet, South Korea & 2017/10/19 & Hong Kong, Pearl River Delta & 2017/10/23 & 4 & Son et al. (2020) \\
\hline 7 & Chilsando Islet, South Korea & $2014 / 11 / 3$ & Taijiang National Park, Taiwan & $2014 / 11 / 5^{*}$ & $2^{*}$ & Jung et al. (2018) \\
\hline 8 & Chilsando Islet, South Korea & 2017/10/19 & Taijiang National Park, Taiwan & 2017/10/30 & 11 & Son et al. (2020) \\
\hline 9 & Gyeonggi Bay, South Korea & 2009 & Hakata Bay, Japan & 2009 & NA & Wood et al. (2013) \\
\hline 10 & Gyeonggi Bay, South Korea & 2014/11/14 & Shimabara Bay, Japan & $2014 / 12 / 7^{*}$ & $23^{*}$ & Jung et al. (2018) \\
\hline 11 & Gyeonggi Bay, South Korea & 2014/10/24 & Shijiu Lake, Inland Jiangsu & $2014 / 11 / 27^{*}$ & $34^{*}$ & Jung et al. (2018) \\
\hline 12 & Gyeonggi Bay, South Korea & 2009 & Wang Lake, Hubei & 2009 & NA & Wood et al. (2013) \\
\hline 13 & Gyeonggi Bay, South Korea & $2014 / 10 / 28$ & Hangzhou Bay, Yangtze River Delta & $2014 / 10 / 30^{*}$ & $2^{*}$ & Jung et al. (2018) \\
\hline 14 & Gyeonggi Bay, South Korea & $2014 / 11 / 2$ & Hangzhou Bay, Yangtze River Delta & $2014 / 11 / 4^{*}$ & $2^{*}$ & Jung et al. (2018) \\
\hline 15 & Gyeonggi Bay, South Korea & 2014/11/8 & Funing Bay, Fujian Coast & $2014 / 11 / 13^{*}$ & $5^{*}$ & Jung et al. (2018) \\
\hline 16 & Gyeonggi Bay, South Korea & 2014/11/3 & Taijiang National Park, Taiwan & $2014 / 11 / 6^{*}$ & $3^{*}$ & Jung et al. (2018) \\
\hline 17 & Gyeonggi Bay, South Korea & $2014 / 11 / 5$ & Taijiang National Park, Taiwan & $2014 / 11 / 29^{*}$ & $24^{*}$ & Jung et al. (2018) \\
\hline 18 & Gyeonggi Bay, South Korea & 2010 & $\begin{array}{l}\text { Tra-sur Flooded Forest, Cambodia/ } \\
\text { Vietnam border }\end{array}$ & 2010 & NA & Wood et al. (2013) \\
\hline 19 & Xingren Island, Liaoning & 2017/11/8 & Nanyi Lake, Anhui & 2017/11/17 & 9 & Jia et al. (2020) \\
\hline 20 & Xingren Island, Liaoning & 2017/10/22 & Poyang Lake, Jiangxi & $2017 / 10 / 30$ & 8 & Jia et al. (2020) \\
\hline 21 & Xingren Island, Liaoning & 2018/10/30 & Yancheng NNR, Yangtze River Delta & 2018/11/2 & 3 & Jia et al. (2020) \\
\hline 22 & Xingren Island, Liaoning & 2018/11/5 & Yancheng NNR, Yangtze River Delta & $2018 / 12 / 5$ & 30 & Jia et al. (2020) \\
\hline 23 & Xingren Island, Liaoning & 2017/10/22 & Hangzhou Bay, Yangtze River Delta & 2017/11/19 & 28 & Jia et al. (2020) \\
\hline 24 & Xingren Island, Liaoning & 2018/10/16 & Taijiang National Park, Taiwan & 2018/10/20 & 4 & Jia et al. (2020) \\
\hline 25 & Gyeonggi Bay, South Korea & 1999/3/23 & Hong Kong, Pearl River Delta & 1999/4/10 & 18 & Ueta et al. (2002) \\
\hline 26 & Gyeonggi Bay, South Korea & 1999/3/27 & Hong Kong, Pearl River Delta & 1999/4/9 & 13 & Ueta et al. (2002) \\
\hline 27 & Gyeonggi Bay, South Korea & 1999/4/13 & Hong Kong, Pearl River Delta & 1999/4/22 & 9 & Ueta et al. (2002) \\
\hline 28 & Gyeonggi Bay, South Korea & 1999/4/13 & Hong Kong, Pearl River Delta & 1999/5/4 & 21 & Ueta et al. (2002) \\
\hline 29 & Gyeonggi Bay, South Korea & $1999 / 3 / 28$ & Taijiang National Park, Taiwan & 1999/4/10 & 13 & Ueta et al. (2002) \\
\hline 30 & Gyeonggi Bay, South Korea & 1999/3/15 & Taijiang National Park, Taiwan & 1999/3/31 & 16 & Ueta et al. (2002) \\
\hline 31 & Yancheng NNR, Yangtze River Delta & 1999/4/23 & Hong Kong, Pearl River Delta & 1999/5/21 & 28 & Ueta et al. (2002) \\
\hline 32 & Yancheng NNR, Yangtze River Delta & 1999/5/14 & Hong Kong, Pearl River Delta & 1999/6/16 & 33 & Ueta et al. (2002) \\
\hline 33 & Nampho, North Korea & 1999/5/18 & Taijiang National Park, Taiwan & 1999/6/11 & 24 & Ueta et al. (2002) \\
\hline 34 & Yilan, Taiwan & 1999/5/6 & Taijiang National Park, Taiwan & 1999/5/10 & 4 & Ueta et al. (2002) \\
\hline
\end{tabular}

ID 1-24 were immature birds captured at breeding sites, all of which finished one complete autumn migration; ID 25-34 were the birds captured in wintering sites and all finished one spring migration, of which ID 25-30 were adults, ID 31-34 were immature birds. *Indicates occasions where the date or the duration were estimated (see "Methods" for more details)

et al. 2020) and inland Jiangsu (Jia River; Jung et al. 2018) in China. With the exception of sites on the Jia River, all other newly located stopover sites were in marine coastal areas (Fig. 2).

\section{Migration routes and timing}

We present a tentative map of possible migration routes based on the combined results of the telemetry studies in Fig. 3, based on 34 migration routes from 34 different individuals. Black-faced Spoonbills usually migrate along the coast of southwest South Korea and in East China, occasionally along river floodplains, as in the case of the Yangtze River. According to telemetry data from the literature, first-year birds initiated their autumn migration from mid-October to mid-November (October $13-$ November 14 ; mean $=$ October $29 ; \mathrm{SD}=8$ days) and arrived to winter quarters in late October to early December (October 15-December 7; mean $=$ November $8 ; \mathrm{SD}=14$ days). The average duration of autumn migration was 9 days $(\mathrm{SD}=10$ days, range $2-34, n=21$ birds; 


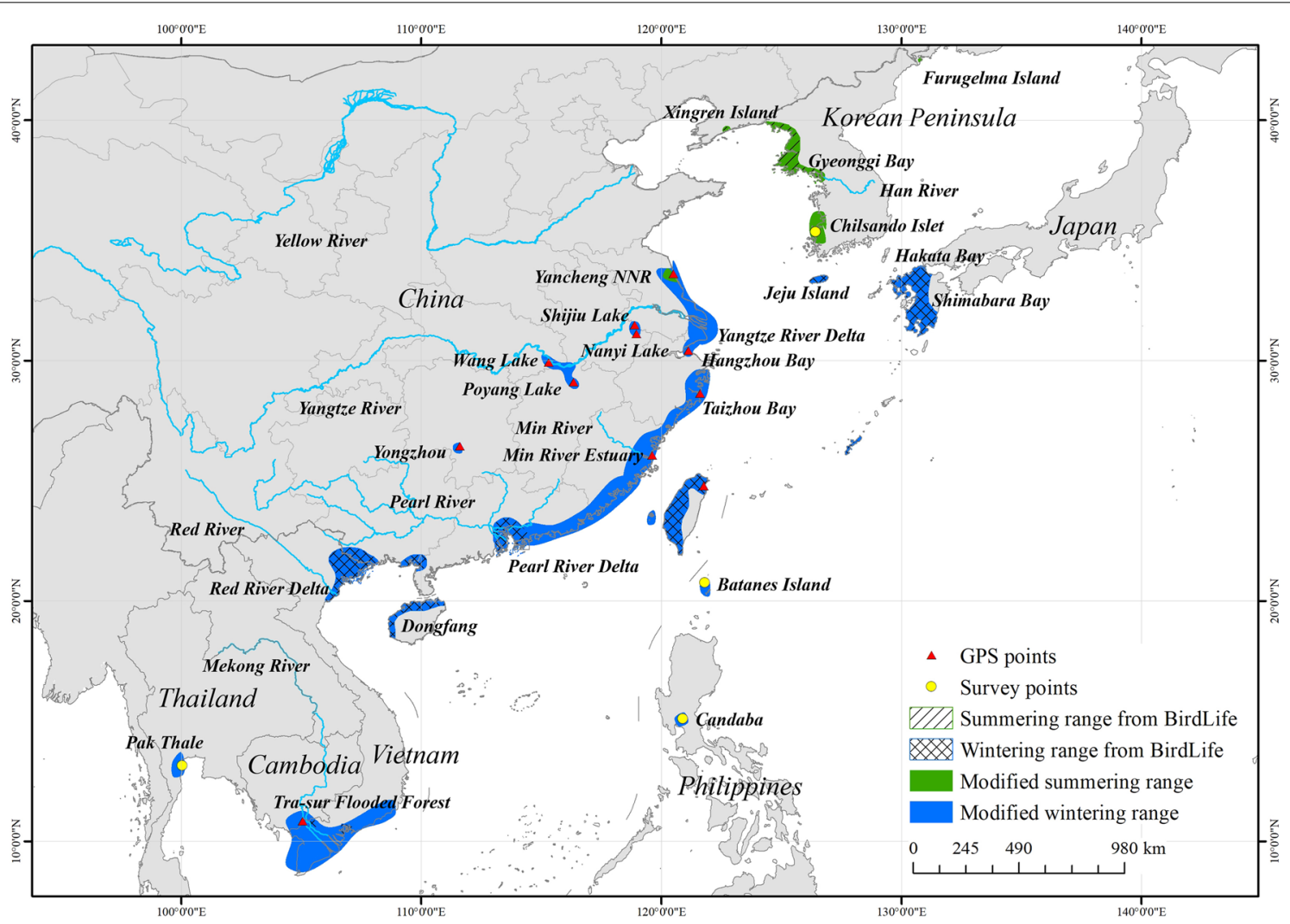

Fig. 1 Revised distribution map of the Black faced Spoonbill (Platalea minor) in East Asia. Summering areas (the west coast of Korean Peninsula, and Xingren Island in Liaoning and Yancheng NNR in Jiangsu Province, China, and Furugelma Island in Russia) are shaded green. Wintering ranges (the west coast of Japan, Jeju Island in South Korea, the east and south coast of China, Yangtze River floodplain, Taiwan of China, Red River Delta and south coast in Vietnam, south coast in Cambodia, south in Thailand and north in Philippines) are shaded blue. Distributions are shown modified from previous maps from BirdLife International and Handbook of Birds of the World (2019, shown as hatching and cross-hatching). Revisions to summer and winter ranges are based on tracking data from the literature (red triangles denote GPS points from when each individual arrived and when they departed the summering and wintering grounds) and field surveys data (yellow circles, including data from Hong Kong Bird Watching Society and data from literature, while Yangtze waterbird survey points were not shown because no Black-faced Spoonbills were counted, see "Methods" for details). All the summering and wintering site/area names mentioned in the paper are shown on the map

Jung et al. 2018; Jia et al. 2020; Son et al. 2020). Based on these tracking results and field survey results (Additional file 1: Table S1), we defined the autumn migration period of Black-faced Spoonbills as October to November inclusive, although a very few individuals started their movements before and continued after this period.

Adult Black-faced Spoonbills started spring migration from mid-March to mid-April (March 15 to April 13; mean $=$ March 30; $\mathrm{SD}=12$ days) and arrived from late March to early May (March 31 to May 4; mean=April 14; $\mathrm{SD}=12$ days). The average migration duration was 16 days $(\mathrm{SD}=6$ days, range 9-24, $n=6$ birds; Ueta et al. 2002). Juveniles started spring migration from late April to late May (April 23 to May 18; mean= May 7; $\mathrm{SD}=11$ days), and arrived from mid-May to midJune (May 10 to June 16; mean = May 30; $S D=17$ days). Average migration duration was 22 days $(\mathrm{SD}=13$ days, range 4-33, $n=4$ birds; Ueta et al. 2002). Based on these tracking results and field survey results (Additional file 1: Table S1), we defined the spring migration in adults as March and April, but in juveniles March to May, for whom the summering period was May to September. The wintering period was defined as December to February inclusive and we thus defined the summer, wintering range and migration staging range according to the distribution of where tracked birds were during these periods. The migration routes of the Black-faced Spoonbills connected the summering sites (Korean Peninsula), stopover sites (east coast of China) and wintering sites (from the southeast coast of China to the south of Philippines and Vietnam) and are based on the results of tracking studies.

Twenty-four immature birds were tracked from breeding sites, including 18 from the main breeding sites in South Korea, and 6 from those in China, although no tracking data were available from Russia. Six of them wintered in inland China, mainly in Yangtze 


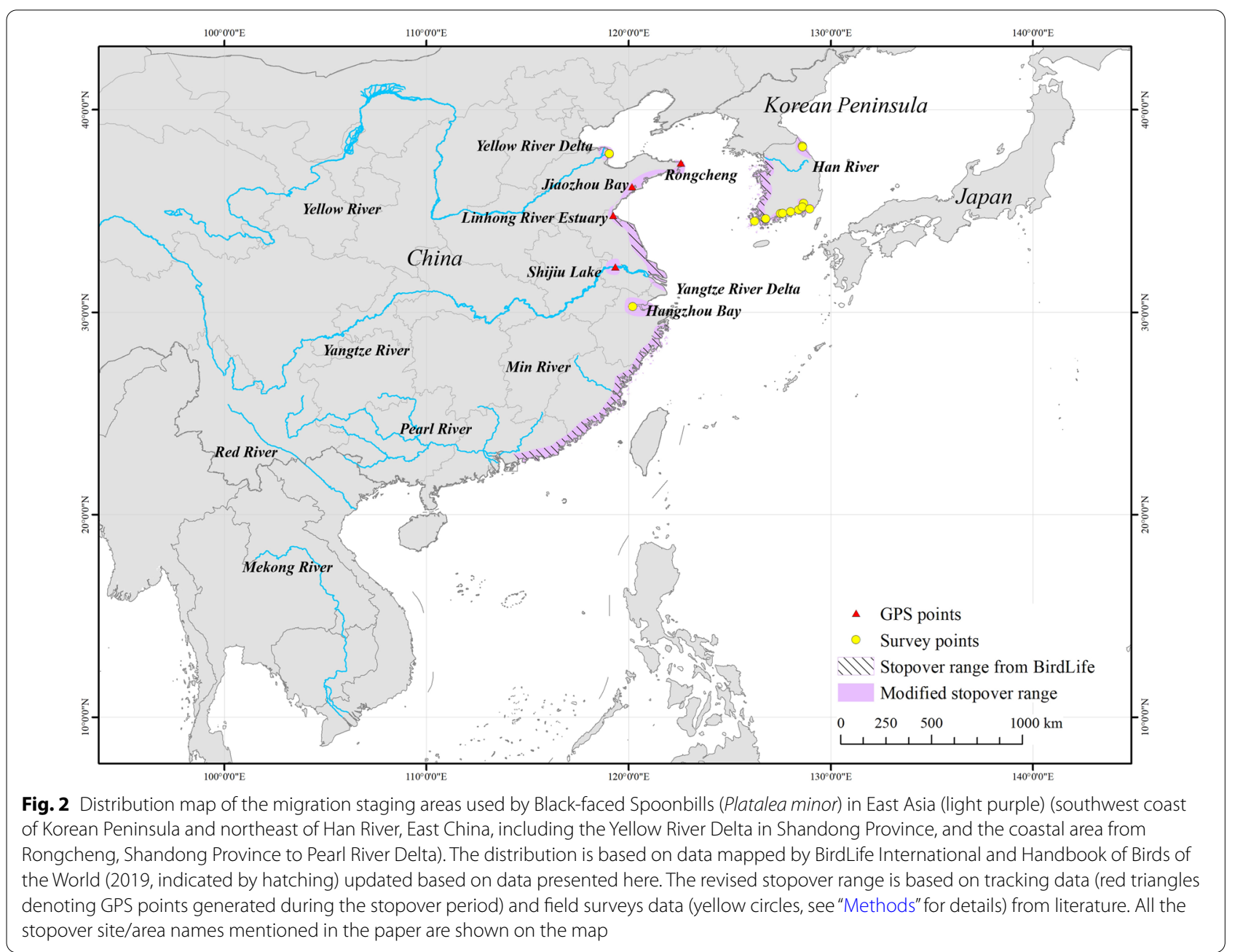

River floodplain; 18 wintered in coastal areas, including Yangtze River Delta, Fujian Coast, Pearl River Delta, on the island of Taiwan, and Japan. From these tracking, the Yangtze River Delta and Yangtze floodplain and the wintering site on the Vietnam/Cambodia border were previously unknown as regular wintering sites (Fig. 1).

From wintering sites in China, four birds (two adults, two juveniles) were tracked from Taiwan and six from Hong Kong (four adults, two juveniles). All six adults summered at the Gyeonggi Bay breeding site, but among the four juveniles, only one summered in the breeding range (Namph in North Korea), while the other three summered at known non-breeding sites (one on Taiwan and two in Yangtze River Delta). The lack of segregation among these tracking results connecting breeding and wintering ranges supports the current hypothesis that there is only one biogeographical population of this species, until further tracking data can show to the contrary.

\section{Abundance estimates and trends}

According to the HKBWS survey results, the population of the Black-faced Spoonbill increased by $300 \%$, from about 1200 to 4864 during 2004 to 2020 (Yu et al. 2020). Since 2004, over $50 \%$ of the Black-faced Spoonbills wintered on Taiwan (with the exceptions of $48 \%$ in 2007 and $47 \%$ in 2011) and these numbers contributed most to the increase of the overall population total. However, the period 2017-2020 also saw a rapid increase in numbers wintering on the Min and Yangtze River Deltas, while numbers wintering on the Pearl River Delta and in Japan have also maintained a steady increase (Table 2; Figs. 4 and 5).

\section{Key sites during the annual life cycle Summering period}

From the literature search, we derived a total of 19 records of Black-faced Spoonbills from 9 sites during the summering period (Additional file 1: Tables S1, S3) 

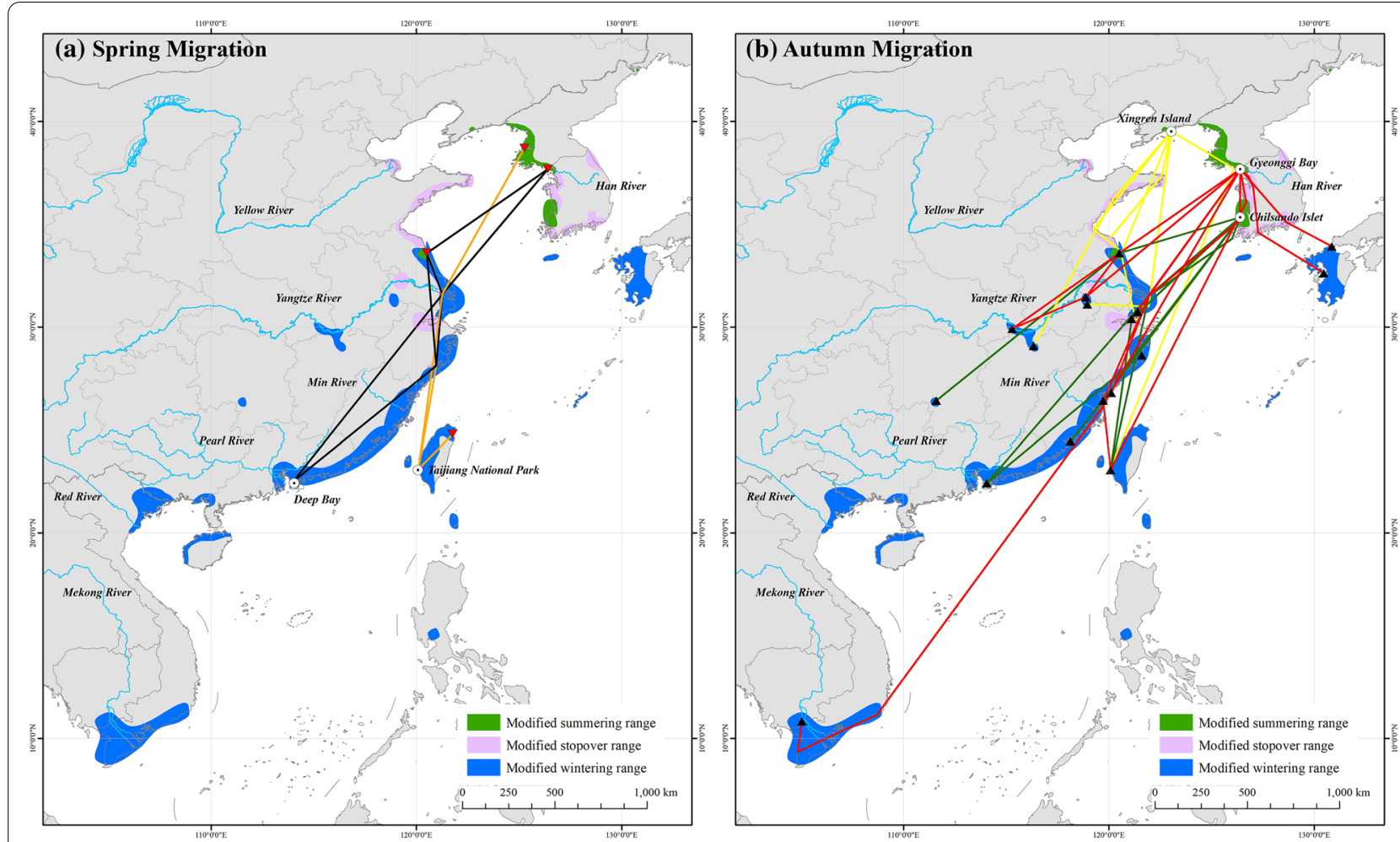

Fig. 3 The migration routes taken by tracked Black-faced Spoonbills (Platalea minor), based on telemetry data from 34 individuals reported in the literature (see "Methods" for details). a Spring migration, including 10 tagged individuals captured at 2 wintering sites: Hong Kong (Deep Bay, $n=6$, black) and Taiwan (Taijiang National Park, $n=4$, orange) in China. b Autumn migration, including 24 tagged individuals captured at three breeding sites: Chilsando Islet ( $n=8$, dark green) and Gyeonggi Bay $(n=10$, red) in South Korea and Xingren Island in Liaoning Province, China ( $n=6$, yellow). Dot-centred circle $=$ the capture sites. Revised summering, wintering, and stopover ranges are shown in green, blue and light purple, respectively. The red inverted and black regular triangles = summer and wintering sites, respectively, used by tracked individuals. The names of all the capture sites and main rivers are shown on the map. All lines are shown as the shortest distances between two sequential fixes, which may not represent the precise routes taken by the birds concerned

including 8 from South Korea, 8 in China, 2 in Russia and 1 in North Korea. Eight survey records revealed 5 breeding sites: Gyeonggi Bay and Chilsando Islet in South Korea, Xingren Island and Yuanbao Island in China, and Furugelma Island in Russia, whereas Gyeonggi Bay had the highest number of breeding individuals of 652 birds (Table 3). Of these sites, Gyeonggi Bay is within WDPA; sites used in Chilsando Islet are partially protected; Xingren Island and Yuanbao Island are protected by provincial government, while Furugelma Island lies outside the known reserve boundaries (Fig. 6a).

\section{Wintering period}

Key wintering sites were defined on $5 \%$ and $1 \%$ thresholds derived from the overall population estimate of 4113 birds, based on average total counts from the annual census during 2016-2020 (Yu et al. 2020). Nineteen internationally important wintering sites (based on the criterion that they supported more than $1 \%$ population at least once since 2004, rounded to a threshold of 40 birds) were identified based on the maximum counts during 20042020 censuses. These comprised 5 important key sites (supporting $>5 \%$ of the population, 200 birds) and 14 regular key sites (1-5\%, 40-200 birds) (Fig. 6b). These 5 important key sites were: Taijiang National Park, Chiayi and Kaoshiung on Taiwan, Xinghua Bay in Fujian, and Deep Bay in Hong Kong and the adjacent Shenzhen. Of all these 19 key wintering sites, 12 sites are currently protected. Seven sites are within WDPA boundaries or NNR boundaries. The Deep Bay area of Hong Kong is partially protected. Haifeng in Guangdong Province, Dongfang in Hainan Province, Taipa-coloane in Macau, and Chiayi on Taiwan are located within a state protected area (Table 4).

\section{Autumn and spring migration periods}

There were 47 records providing some dated information about stopover sites (Table 5). Chongming Island in Shanghai (Yangtze River Delta) and Xinghua Bay in Fujian Province were the most intensively used stopover 
Table 2 Annual counts of Black-faced Spoonbills (Platalea minor) in ten regions in January during 2004-2020

\begin{tabular}{|c|c|c|c|c|c|c|c|c|c|c|}
\hline Year & Korea & Japan & $\begin{array}{l}\text { Yangtze } \\
\text { River Delta }\end{array}$ & Fujian Coast & Taiwan & $\begin{array}{l}\text { Pearl River } \\
\text { Delta }\end{array}$ & Hainan & Thailand & Philippines & Total \\
\hline 2004 & 23 & 147 & 22 & 1 & 633 & 293 & 62 & 2 & NA & 1198 \\
\hline 2005 & 21 & 92 & 29 & 63 & 757 & 389 & 77 & NA & NA & 1484 \\
\hline 2006 & 21 & 148 & 9 & 69 & 822 & 453 & 6 & NA & NA & 1602 \\
\hline 2007 & 20 & 191 & 14 & 86 & 790 & 476 & 8 & NA & NA & 1630 \\
\hline 2008 & 28 & 192 & 5 & 115 & 1030 & 527 & 11 & 5 & NA & 1962 \\
\hline 2009 & 25 & 166 & 0 & 99 & 1104 & 460 & 8 & NA & 1 & 1926 \\
\hline 2010 & 12 & 198 & 0 & 103 & 1280 & 577 & 7 & 1 & 0 & 2224 \\
\hline 2011 & 14 & 220 & 3 & 53 & 834 & 536 & 57 & 1 & 0 & 1767 \\
\hline 2012 & 17 & 196 & 57 & 135 & 1561 & 536 & 31 & 2 & 0 & 2570 \\
\hline 2013 & 8 & 223 & 42 & 47 & 1624 & 485 & 32 & 1 & NA & 2501 \\
\hline 2014 & 8 & 276 & 23 & 33 & 1658 & 466 & 36 & 1 & 0 & 2541 \\
\hline 2015 & 14 & 293 & 13 & 32 & 2034 & 622 & 54 & NA & $\mathrm{NA}$ & 3102 \\
\hline 2016 & 23 & 247 & 4 & 124 & 2060 & 623 & 77 & 0 & 1 & 3167 \\
\hline 2017 & 18 & 305 & 54 & 118 & 2601 & 608 & 61 & NA & NA & 3827 \\
\hline 2018 & 14 & 305 & 93 & 295 & 2191 & 626 & 66 & 1 & 3 & 3659 \\
\hline 2019 & 23 & 324 & 188 & 281 & 2403 & 708 & 83 & 1 & 3 & 4079 \\
\hline 2020 & 24 & 339 & 196 & 338 & 2783 & 726 & 86 & NA & 3 & 4555 \\
\hline
\end{tabular}

The ten regions were identified based on the distribution of the surveyed wintering sites during 2004-2020 conducted by HKBWS. Counts of Yangtze River Delta includes counts of Shanghai, Zhejiang, and Jiangsu Province in China; counts of Fujian Coast includes counts of Fujian Province in China; counts of Pearl River Delta includes counts of Hong Kong, Macau, and Guangdong Province in China

sites. Numbers staging at the Yellow River Delta from 2002 to 2005 might have decreased during these years, but long-term regular monitoring activities at this site were lacking. The most recent records (110 birds in October and 142 birds in December) were 2 total counts from 7 sites along the Zhejiang coast in 2016. Twentythree key sites were identified by meeting the threshold of $0.25 \%$ population and staging for 7 days from the field survey results and satellite tracking data. Among these sites, 4 were located within NNR boundaries: Yellow River Delta, Yancheng NNR, Chongming Island and Min River Estuary (Fig. 6c, d).

Data from 24 tracked individuals revealed 26 autumn stopover sites (Fig. 7), of which 7 sites were used for 8-31 days (based on maximum possible stopover duration), 9 sites for the staging of 2-7 days, and 10 sites for staging of one day only. Chongming Island of Shanghai recorded the highest number of tracked individuals (9), followed by 3 individuals at Yancheng NNR of Jiangsu Province and 2 at Luoyuan Bay of Fujian Province.

\section{Discussion}

In this paper, we integrated data from field surveys and satellite tracking studies to refine the existing distribution range of the Black-faced Spoonbill, identified some new key sites and reviewed the conservation status of these sites. We recommend including Yellow Sea coastal areas (e.g., the Yancheng NNR in Jiangsu Province; Fig. 1) within the summer range of this species. We also found that Black-faced Spoonbills were reported summering in the Min River Estuary (several immature birds; Liu 2006) and Yilan, Taiwan (one tracked immature; Ueta et al. 2002), but consultation with local experts confirmed that these records were too few and irregular to justify including these sites as summering sites. Historically, Longtan Reservoir (Liaoning Province) was reported to be used by a dozen Black-faced Spoonbills in March 1993 (Qiu 2007a), but as this site lies well away from the known migration routes and the information is relatively old, this site was not included in the analysis of this study. Further survey is needed to confirm whether Black-faced Spoonbills still occur regularly there in the absence of recent records.

We also suggest the inclusion of wetlands on the east coast of China within the regular wintering area of this species. The Yangtze River floodplain wetlands need more surveys to elucidate the true status of the wintering Black-faced Spoonbills. Satellite tracking results in conjunction with a few isolated ground observations (e.g., Yu and Swennen 2005) showed that Black-faced Spoonbills could be found in freshwater inland habitats during the winter (Table 6, Fig. 3). With the increasing trend in the wintering population of this species, it could be speculated that new wintering flocks could be found there in the future (Wood et al. 2013). Records in these inland freshwater habitats gives us a hint that some 

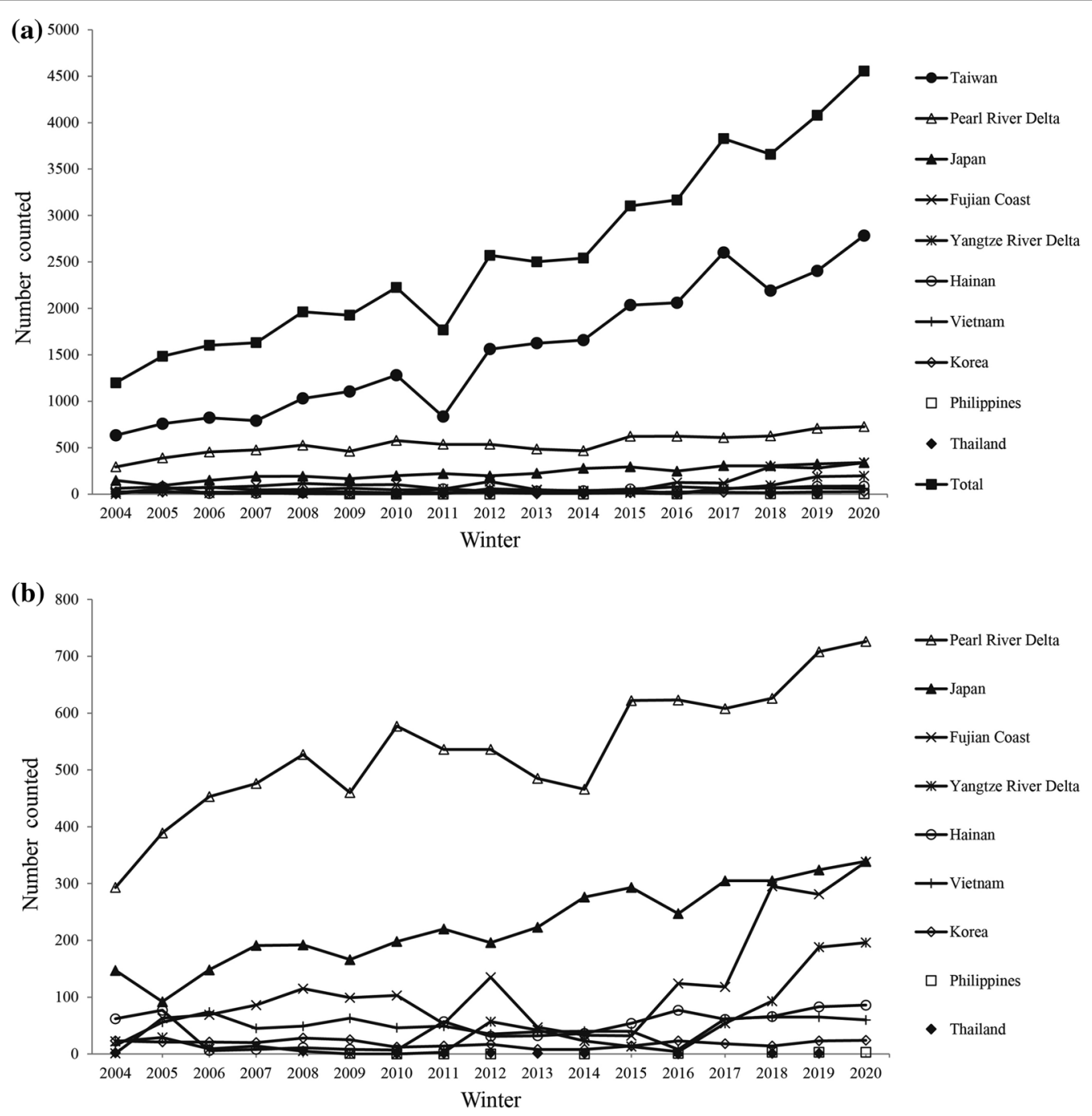

Fig. 4 a Numbers and trends of wintering Black-faced Spoonbills (Platalea minor) in different geographic units during 2004-2020. All figures were provided courtesy of the HKBWS. $\mathbf{b}$ Same figures excluding Taiwan shown in smaller scale $(<800$ individuals) for better clarity of smaller count figures

fledging Black-faced Spoonbills could mix with the congeneric Eurasian Spoonbills (Platalea leucorodia) wintering in this area which were counted in large numbers (Additional file 1: Table S4), as both these species have already been reported together using freshwater habitats in inland wintering sites ( $\mathrm{Yu}$ and Swennen 2005; Wood et al. 2013; Sullender et al. 2016). Public awareness of the Black-faced Spoonbill should be raised among the waterbird surveyors, wetland managers and birdwatching communities in these areas to alert them to the possibility of their occurrence in these previously unusual wintering areas. Local ornithologists might not be aware that the Black-faced Spoonbill, thought to be a coastal species, could also be found in these freshwater habitats, and that single individuals have the potential to be mixed in with the larger wintering flocks of Eurasian Spoonbills. In addition, hybridization between the two species makes it possible that a certain proportion of hybrid individuals exist in Eurasian Spoonbill colonies on the mainland. Since observed hybrid individuals appear very similar to Black-faced Spoonbills (Kwon et al. 2017; Tiunov 2021), careful monitoring is necessary in both breeding and wintering areas to determine their numbers and distribution throughout the range. Local observers and researchers should also be encouraged to report sightings of Black-faced Spoonbills to the international coordinator of the annual Black-faced Spoonbill winter census, as this will extend census coverage and improve our assessment 

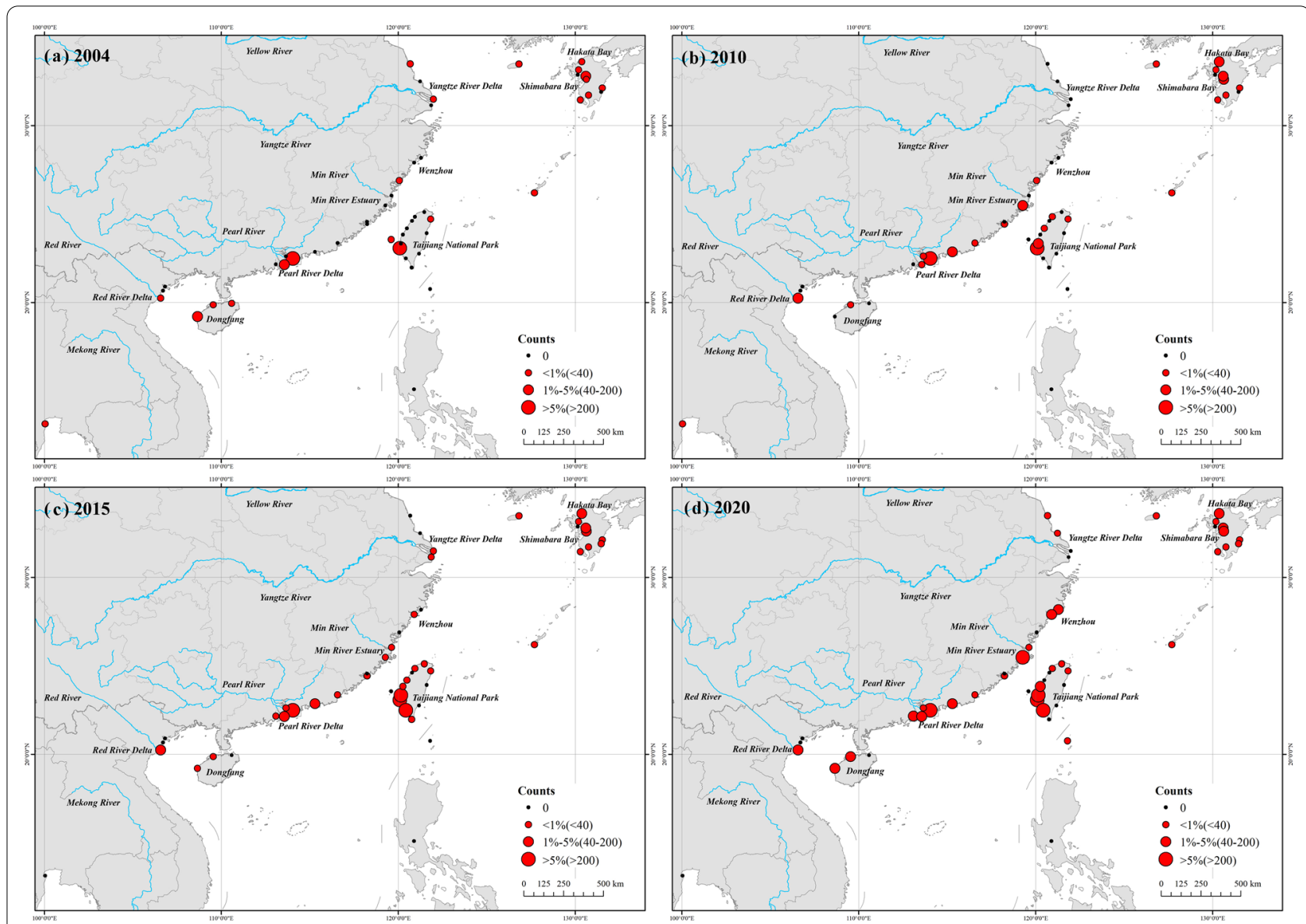

Fig. 5 Changes in distribution and abundance of Black-faced Spoonbills (Platalea minor) counted at internationally important sites in 2004, 2010, 2015 and 2020. a January 2004 (four internationally important sites, including two with 1\%-5\% of the average of the 2016-2020 wintering counts, 40-200, and two with > 5\%, 200). b January 2010 (seven internationally important sites, including five with 1\%-5\% of birds counted, 40-200, and two with > 5\%, 200). c January 2015 (nine internationally important sites, including six with 1-5\% of birds counted, 40-200, and three with > 5\%, 200). d January 2020 (fourteen internationally important sites, including ten with $1 \%-5 \%$ of birds counted, $40-200$, and four with $>5 \%, 200$ ). In recent years, there has been a rapid increase in wintering numbers on the Min and Yangtze River Deltas. Black circles indicate sites that were visited, but where no Black-faced Spoonbills were present. The size of the red circles indicates the numbers counted as a proportion of individuals, in relation to the total wintering numbers counted in 2020

Table 3 Breeding sites of the Black-faced Spoonbill (Platalea minor) revealed by field survey records, as well as the maximum numbers of birds recorded in summer

\begin{tabular}{llllllll}
\hline Site name & Region & Longitude $\left({ }^{\circ} \mathrm{E}\right)$ & Latitude $\left({ }^{\circ} \mathbf{N}\right)$ & Number of birds & Year & Conservation status & Resource \\
\hline Gyeonggi Bay area & $\begin{array}{l}\text { Gyeonggi, South } \\
\text { Korea }\end{array}$ & 126.40 & 37.69 & 652 & 2006 Within WDPA & NRICH (2007) \\
Chilsando Islet & $\begin{array}{l}\text { South Jeolla, South } \\
\text { Korea }\end{array}$ & 126.41 & 35.35 & 100 & 2014 & Partially protected & NRICH (2014) \\
Yuanbao Island & $\begin{array}{l}\text { Liaoning, China } \\
\text { Xingren Island }\end{array}$ & 123.09 & 39.50 & 14 & 2007 Locally protected & Qiu (2007a) \\
Furugelma Island & Liaoning, China & 123.05 & 39.53 & 49 nests & 2019 Locally protected & Jia et al. (2020) \\
\hline
\end{tabular}

In South Korea, Gyeonggi Bay area currently falls within existing protected area boundaries and sites used in Chilsando Islet are partially protected. In China, Yuanbao Island and Xingren Island are shown as provincial protected areas. The partially and locally protected areas were not within the current national protected area boundary 

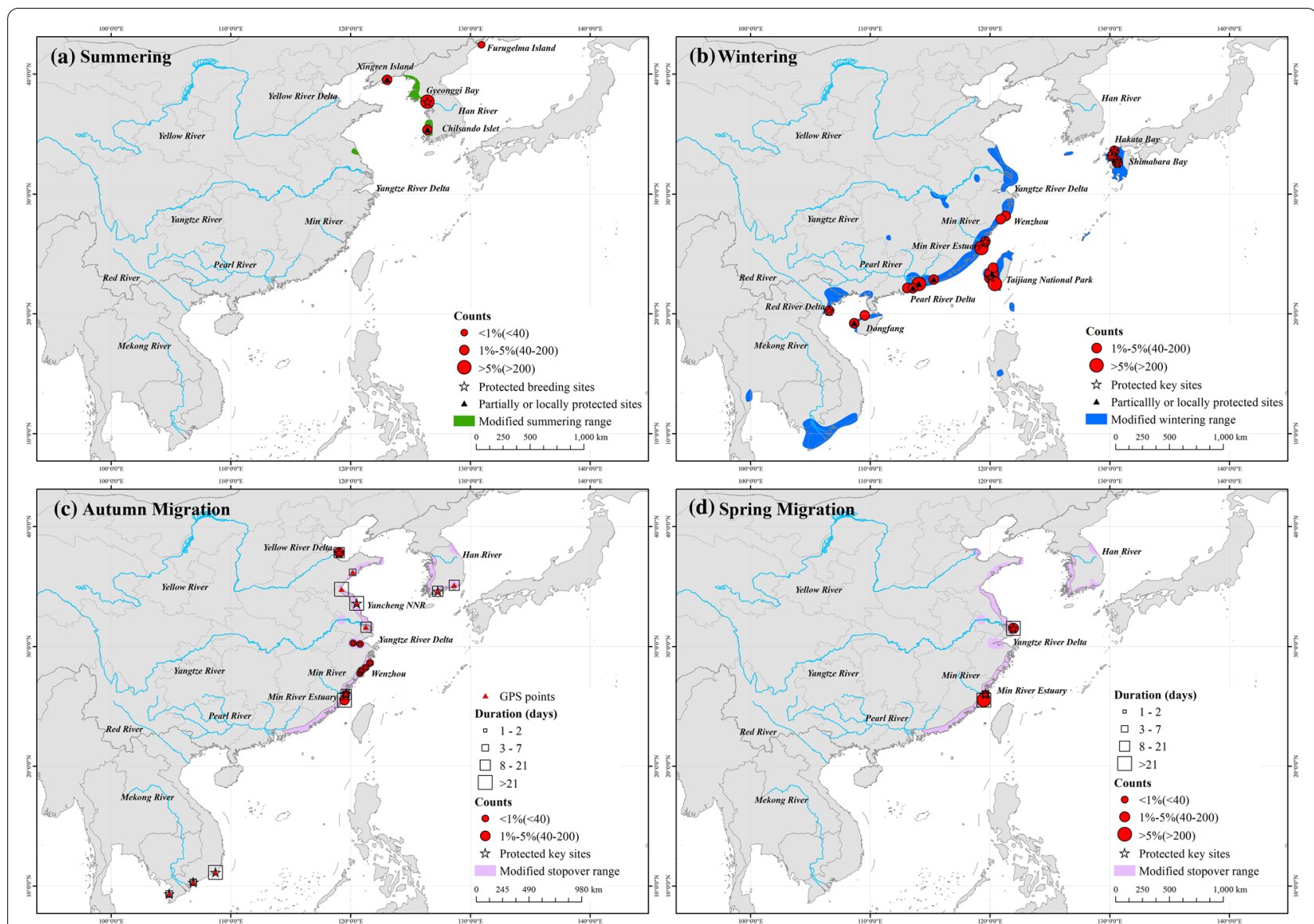

Fig. 6 Internationally important sites for Black-faced Spoonbills (Platalea minor) in relation to annual life cycle and protected areas. a Summering = May-September, including four breeding sites (Yuanbao Island is very close to Xingren Island so here are combined as one site, labelled Xingren Island). b Wintering=December-February, including 19 internationally important sites, 5 important key sites (>5\% of the 2016-2020 wintering counts, 200) and 14 regular key sites (1-5\%, 40-200). c Autumn Migration=October-November, including 9 key sites (used by more than ten birds, the $0.25 \%$ of the average of the 2016-2020 wintering counts, 10 birds, or used by tagged individuals for more than 7 consecutive days). $\mathbf{d}$ Spring Migration= March-April or May, including 4 key sites (the definition is the same as the Autumn Migration period). Revised summering, wintering, and stopover ranges are shaded in green, blue and light purple, respectively

of the total population size. Given that the Black-faced Spoonbill population is expanding (based on the results of the winter census), further expansion of its wintering range into the wetlands along the Yangtze River remains highly likely in the future (Wood et al. 2013; Takano et al. 2014). Migratory waterbirds are known to show exploratory behavior during migration and colonize new staging and wintering areas (Baker 1980; Jansen 1981; Galvan et al. 2003). Black-faced Spoonbills have been reported migrating in age-specific groups (Ueta and Higuchi 2002; Wood et al. 2013), and since all birds tracked on autumn migration were immature birds (Wood et al. 2013; Jung et al. 2018; Jia et al. 2020; Son et al. 2020), their migration (thought independent of adults) may explain such exploratory patterns.
One major drawback of recent tracking studies of Black-faced Spoonbills is that results are heavily biased towards those from trapped and tracked fledglings, because they were more easily caught than the adults on the breeding sites (e.g., Wood et al. 2013; Son et al. 2020). Hence, information about the movements of individuals of other age groups, i.e., subadults and adults are still lacking, despite Ueta et al. (2002) tracking six adults to study their spring migration in 1999. Data retrieved from immature birds showed them not returning to the breeding sites, but remaining on their wintering grounds, or at least in southern parts of the normal summer distributional range (Ueta et al. 2002). Therefore, tracking of adult or sub-adult Black-faced Spoonbills could provide more information about their migration schedules, 
Table 4 Internationally important wintering sites for the Black-faced Spoonbill (Platalea minor) showing maximum counts and current conservation status

\begin{tabular}{|c|c|c|c|c|c|c|}
\hline Site name & Region & Longitude $\left({ }^{\circ} \mathrm{E}\right)$ & Latitude $\left({ }^{\circ} \mathrm{N}\right)$ & $\begin{array}{l}\text { Maximum } \\
\text { counts }\end{array}$ & Year & Conservation status \\
\hline Ariake Sea North & Japan & 130.19 & 33.14 & 43 & 2019 & Within WDPA \\
\hline Hakata Bay & Japan & 130.37 & 33.60 & 66 & 2007 & Within WDPA \\
\hline Shimabara Bay & Japan & 130.60 & 32.78 & 102 & 2020 & Within WDPA \\
\hline Yatsushiro Sea North & Japan & 130.63 & 32.59 & 95 & 2017 & Within WDPA \\
\hline Xuanmun Bay & Zhejiang, China & 121.29 & 28.17 & 97 & 2020 & Unprotected \\
\hline Wenzhou & Zhejiang, China & 120.89 & 27.90 & 89 & 2019 & Unprotected \\
\hline Min River Estuary & Fujian, China & 119.62 & 26.03 & 71 & 2017 & Within NNRs \\
\hline Xinghua Bay & Fujian, China & 119.27 & 25.48 & 323 & 2020 & Unprotected \\
\hline Haifeng & Guangdong, China & 115.29 & 22.86 & 198 & 2020 & Locally protected \\
\hline Jiangmun & Guangdong, China & 113.08 & 22.16 & 90 & 2020 & Unprotected \\
\hline Lingao & Hainan, China & 109.53 & 19.87 & 42 & 2020 & Unprotected \\
\hline Dongfang & Hainan, China & 108.65 & 19.21 & 68 & 2005 & Locally protected \\
\hline Deep Bay & Hong Kong, China & 114.04 & 22.49 & 462 & 2010 & Partially protected \\
\hline Taipa-coloane & Macau, China & 113.56 & 22.14 & 61 & 2016 & Locally Protected \\
\hline Yunlin & Taiwan, China & 120.26 & 23.84 & 102 & 2020 & Unprotected \\
\hline Chiayi & Taiwan, China & 120.14 & 23.33 & 870 & 2016 & Locally protected \\
\hline Taijiang National Park & Taiwan, China & 120.08 & 23.07 & 1839 & 2020 & Within WDPA \\
\hline Kaoshiung & Taiwan, China & 120.41 & 22.49 & 257 & 2018 & Unprotected \\
\hline Xuan Thuy National Park & Vietnam & 106.57 & 20.25 & 74 & 2006 & Within WDPA \\
\hline
\end{tabular}

The key wintering sites ( $>1 \%$ Criterion: 40 birds, $n=14$ ) and important key sites ( $>5 \%$ Criterion: 200 birds, shown in bold, $n=5$ ) were identified based on the maximum counts during 2004-2020 from the Hong Kong Bird Watching Society (HKBWS). Seven sites currently fall within existing protected area boundaries. In addition, areas used in Deep Bay are partially protected and the Haifeng, Dongfang, Chiayi and Taipa-coloane sites are shown as provincial or state protected area, but the areas used by birds were not within the current national protected area boundary

staging site use and the distribution range of this segment of the population. This also suggests that the immature birds do not usually undertake the long non-stop flight of crossing the Yellow Sea to reach the Korean Peninsula for summer. By doing so, young individuals could also avoid competition with breeding birds (Kokko 1999).

We can synthesize information from tracking studies to generate distribution map for the Black-faced Spoonbill's stopover sites of autumn migration (Fig. 7), but data were insufficient to do the same for spring migration. The literature review found three important sites in spring migration: Yancheng NNR in Jiangsu Province (three birds); Shanghai (four) and Yueqing in Zhejiang Province (seven) (Ueta et al. 2002). This information is similar to the results from autumn migration, suggesting that these three areas could be important stopover sites of the Black-faced Spoonbills during both migration episodes. However, field surveys of these sites were still inadequate to record the actual frequency of use by Black-faced Spoonbills of these sites in spring (Fig. 6; Table 5). For this reason, we urge systematic monitoring activities during the migration period especially from mid-October to mid-November and from mid-March to mid-April at these sites, to generate information on abundance, turnover and stopover ecology of this species, as well as the relative importance of the stopover sites.

On the breeding areas, field surveys were regularly conducted in South Korea (Kwon et al. 2015; Kang et al. 2016), China (Ding et al. 2000; Qiu 2007a, b; Jia et al. 2020) and Russia (Tiunov and Katin 2020; Tiunov 2021), but no survey or regular monitoring was conducted at sites within North Korea. As the current wintering population is more than 5200 individuals (Yu et al. 2021) and non-systematic summer counts recorded less than 1000 individuals (Additional file 1: Table S1), this discrepancy suggests that some breeding concentrations and aggregations of non-breeding immature individuals in summer remained undiscovered. These sites could be of conservation importance for the Black-faced Spoonbill based on the numbers of these missing individuals, so more field surveys here are urgently needed.

Black-faced Spoonbills are sensitive to human disturbance and benefit from protection of the sites (Wei et al. 2005; Zhang et al. 2010, 2012; Henmi and Takano 2012; Sung et al. 2018). The Black-faced Spoonbill takes five years to reach sexually maturity (Yu 2005), which means the protection of the sites for these segments of the population during staging and wintering period are 
Table 5 Stopover sites with available arrival/departure dates of the Black-faced Spoonbill (Platalea minor) revealed by field survey records and telemetry data

\begin{tabular}{|c|c|c|c|c|c|c|c|c|c|}
\hline Stage & Site name & Region & $\begin{array}{l}\text { Longitude } \\
\left({ }^{\circ} \mathrm{E}\right)\end{array}$ & $\begin{array}{l}\text { Latitude } \\
\left({ }^{\circ} \mathrm{N}\right)\end{array}$ & $\begin{array}{l}\text { Number of } \\
\text { birds }\end{array}$ & Arrival time & $\begin{array}{l}\text { Departure } \\
\text { time }\end{array}$ & $\begin{array}{l}\text { Duration } \\
\text { (days) }\end{array}$ & Resource \\
\hline \multirow{30}{*}{$\begin{array}{l}\text { Autumn } \\
\text { migration } \\
\text { (Oct-Nov) }\end{array}$} & Gyeonggi Bay area & South Korea & 126.40 & 37.69 & 1 (tracked) & $2018 / 10 / 17^{*}$ & 2018/10/19* & 2 & Jia et al. (2020) \\
\hline & Ansan & South Korea & 126.82 & 37.31 & 1 (tracked) & $2014 / 11 / 15^{*}$ & $2014 / 11 / 17^{*}$ & 2 & Jung et al. (2018) \\
\hline & Cheonan & South Korea & 127.03 & 36.80 & 1 (tracked) & $2014 / 11 / 17^{*}$ & 2014/11/18* & 1 & Jung et al. (2018) \\
\hline & Seocheon County & South Korea & 126.69 & 36.07 & 1 (tracked) & $2014 / 11 / 4^{*}$ & $2014 / 11 / 5^{*}$ & 1 & Jung et al. (2018) \\
\hline & Yeonggwang County & South Korea & 126.38 & 35.19 & 1 (tracked) & $2014 / 11 / 6^{*}$ & $2014 / 11 / 7^{*}$ & 1 & Jung et al. (2018) \\
\hline & Goheung-gun & South Korea & 127.27 & 34.61 & 1 (tracked) & $2014 / 11 / 18^{*}$ & $2014 / 12 / 6^{*}$ & 18 & Jung et al. (2018) \\
\hline & Hajo-do & South Korea & 125.99 & 34.30 & 1 (tracked) & $2014 / 11 / 4^{*}$ & $2014 / 11 / 5^{*}$ & 1 & Jung et al. (2018) \\
\hline & Nagasaki & Japan & 129.82 & 32.73 & 1 (tracked) & $2014 / 12 / 6^{*}$ & $2014 / 12 / 7^{*}$ & 1 & Jung et al. (2018) \\
\hline & Yellow River Delta & $\begin{array}{l}\text { Shandong, } \\
\text { China }\end{array}$ & 119.04 & 37.82 & 49 & $2002 / 10 / 27$ & $2002 / 11 / 13$ & 17 & Shan et al. (2005) \\
\hline & Yellow River Delta & $\begin{array}{l}\text { Shandong, } \\
\text { China }\end{array}$ & 119.04 & 37.82 & 15 & $2003 / 10 / 23$ & $2003 / 11 / 10$ & 18 & Shan et al. (2005) \\
\hline & Yellow River Delta & $\begin{array}{l}\text { Shandong, } \\
\text { China }\end{array}$ & 119.04 & 37.82 & 11 & $2004 / 11 / 2$ & $2004 / 11 / 15$ & 13 & Shan et al. (2005) \\
\hline & Rongcheng NNR & $\begin{array}{l}\text { Shandong, } \\
\text { China }\end{array}$ & 122.58 & 37.36 & 1 (tracked) & $2018 / 10 / 31^{*}$ & $2018 / 11 / 2^{*}$ & 3 & Jia et al. (2020) \\
\hline & Rongcheng NNR & $\begin{array}{l}\text { Shandong, } \\
\text { China }\end{array}$ & 122.58 & 37.36 & 3 & $2002 / 11 / 20$ & NA & NA & $\begin{array}{l}\text { Zhao et al. } \\
\text { (2003) }\end{array}$ \\
\hline & Jiaozhou Bay & $\begin{array}{l}\text { Shandong, } \\
\text { China }\end{array}$ & 120.17 & 36.19 & 1 (tracked) & $2017 / 10 / 22^{*}$ & $2017 / 10 / 29^{*}$ & 7 & Jia et al. (2020) \\
\hline & Linhong Estuary & $\begin{array}{l}\text { Jiangsu, } \\
\text { China }\end{array}$ & 119.23 & 34.78 & 1 (tracked) & $2018 / 11 / 6^{*}$ & $2018 / 12 / 4^{*}$ & 28 & Jia et al. (2020) \\
\hline & Yancheng NNR & $\begin{array}{l}\text { Jiangsu, } \\
\text { China }\end{array}$ & 120.51 & 33.60 & 1 (tracked) & $2014 / 10 / 26^{*}$ & $2014 / 11 / 27^{*}$ & 31 & Jung et al. (2018) \\
\hline & Yancheng NNR & $\begin{array}{l}\text { Jiangsu, } \\
\text { China }\end{array}$ & 120.51 & 33.60 & 1 (tracked) & $2017 / 10 / 25^{*}$ & $2017 / 11 / 18^{*}$ & 23 & Jia et al. (2020) \\
\hline & Yancheng NNR & Jiangsu, China & 120.51 & 33.60 & 1 (tracked) & $2017 / 10 / 13^{*}$ & $2017 / 10 / 14^{*}$ & 1 & Son et al. (2020) \\
\hline & Dafeng & Jiangsu, China & 120.50 & 33.20 & 1 (tracked) & $2014 / 10 / 25^{*}$ & $2014 / 10 / 26^{*}$ & 1 & Jung et al. (2018) \\
\hline & Jia River & Jiangsu, China & 119.34 & 32.23 & 1 (tracked) & $2014 / 11 / 27^{*}$ & $2014 / 11 / 28^{*}$ & 1 & Jung et al. (2018) \\
\hline & $\begin{array}{l}\text { Yangtze River } \\
\text { Estuary }\end{array}$ & $\begin{array}{l}\text { Shanghai, } \\
\text { China }\end{array}$ & 121.27 & 31.60 & 1 (tracked) & $2014 / 11 / 8^{*}$ & $2014 / 11 / 29^{*}$ & 21 & Jung et al. (2018) \\
\hline & Yangtze River Estuary & $\begin{array}{l}\text { Shanghai, } \\
\text { China }\end{array}$ & 121.27 & 31.60 & 1 (tracked) & $2014 / 11 / 6^{*}$ & $2014 / 11 / 7^{*}$ & 1 & Jung et al. (2018) \\
\hline & Yangtze River Estuary & $\begin{array}{l}\text { Shanghai, } \\
\text { China }\end{array}$ & 121.27 & 31.60 & 1 (tracked) & $2017 / 11 / 9^{*}$ & $2017 / 11 / 11^{*}$ & 2 & Jia et al. (2020) \\
\hline & Yangtze River Estuary & $\begin{array}{l}\text { Shanghai, } \\
\text { China }\end{array}$ & 121.27 & 31.60 & 1 (tracked) & $2017 / 10 / 30^{*}$ & $2017 / 10 / 31^{*}$ & 1 & Son et al. (2020) \\
\hline & Yangtze River Estuary & $\begin{array}{l}\text { Shanghai, } \\
\text { China }\end{array}$ & 121.27 & 31.60 & 1 (tracked) & $2017 / 10 / 28^{*}$ & $2017 / 11 / 1^{*}$ & $4^{*}$ & Son et al. (2020) \\
\hline & $\begin{array}{l}\text { Yangtze River } \\
\text { Estuary }\end{array}$ & $\begin{array}{l}\text { Shanghai, } \\
\text { China }\end{array}$ & 121.27 & 31.60 & 1 (tracked) & 2017/10/19* & $2017 / 10 / 29^{*}$ & $10^{*}$ & Son et al. (2020) \\
\hline & Chongming Island & $\begin{array}{l}\text { Shanghai, } \\
\text { China }\end{array}$ & 121.95 & 31.52 & 1 (tracked) & $2014 / 10 / 29^{*}$ & $2014 / 10 / 30^{*}$ & 1 & Jung et al. (2018) \\
\hline & Chongming Island & $\begin{array}{l}\text { Shanghai, } \\
\text { China }\end{array}$ & 121.95 & 31.52 & 1 (tracked) & $2014 / 11 / 9^{*}$ & $2014 / 11 / 11^{*}$ & 2 & Jung et al. (2018) \\
\hline & Chongming Island & $\begin{array}{l}\text { Shanghai, } \\
\text { China }\end{array}$ & 121.95 & 31.52 & 1 (tracked) & $2014 / 11 / 3^{*}$ & $2014 / 11 / 4^{*}$ & 1 & Jung et al. (2018) \\
\hline & $\begin{array}{l}\text { Seven Wetlands in } \\
\text { Zhejiang }\end{array}$ & $\begin{array}{l}\text { Zhejiang, } \\
\text { China }\end{array}$ & 120.92 & 28.84 & 142 & 2016.12 .1 & NA & NA & Jin et al. (2017) \\
\hline
\end{tabular}


Table 5 (continued)

\begin{tabular}{|c|c|c|c|c|c|c|c|c|c|}
\hline Stage & Site name & Region & $\begin{array}{l}\text { Longitude } \\
\left({ }^{\circ} \mathrm{E}\right)\end{array}$ & $\begin{array}{l}\text { Latitude } \\
\left({ }^{\circ} \mathrm{N}\right)\end{array}$ & $\begin{array}{l}\text { Number of } \\
\text { birds }\end{array}$ & Arrival time & $\begin{array}{l}\text { Departure } \\
\text { time }\end{array}$ & $\begin{array}{l}\text { Duration } \\
\text { (days) }\end{array}$ & Resource \\
\hline & $\begin{array}{l}\text { Seven Wetlands in } \\
\text { Zhejiang }\end{array}$ & $\begin{array}{l}\text { Zhejiang, } \\
\text { China }\end{array}$ & 120.92 & 28.84 & 110 & 2016.10 .23 & NA & NA & Jin et al. (2017) \\
\hline & Taizhou Bay & $\begin{array}{l}\text { Zhejiang, } \\
\text { China }\end{array}$ & 121.61 & 28.63 & 1 (tracked) & $2014 / 11 / 4^{*}$ & $2014 / 11 / 5^{*}$ & 1 & Jung et al. (2018) \\
\hline & Ou River Estuary & $\begin{array}{l}\text { Zhejiang, } \\
\text { China }\end{array}$ & 120.74 & 27.94 & 1 (tracked) & 2017/10/19* & $2017 / 10 / 22^{*}$ & $3^{*}$ & Son et al. (2020) \\
\hline & Yueqing & $\begin{array}{l}\text { Zhejiang, } \\
\text { China }\end{array}$ & 120.97 & 28.12 & 1 (tracked) & $2014 / 11 / 5^{*}$ & $2014 / 11 / 6^{*}$ & 1 & Jung et al. (2018) \\
\hline & Funing Bay & Fujian, China & 120.13 & 26.81 & 1 (tracked) & $2014 / 11 / 12^{*}$ & $2014 / 11 / 14^{*}$ & 1 & Jung et al. (2018) \\
\hline & Luoyuan Bay & Fujian, China & 119.72 & 26.43 & 1 (tracked) & $2014 / 11 / 30^{*}$ & $2014 / 12 / 1^{*}$ & 1 & Jung et al. (2018) \\
\hline & Luoyuan Bay & Fujian, China & 119.72 & 26.43 & 1 (tracked) & $2014 / 11 / 6^{*}$ & $2014 / 11 / 11^{*}$ & 5 & Jung et al. (2018) \\
\hline & Min River Estuary & Fujian, China & 119.62 & 26.04 & 22 & $2004 / 10 / 27$ & 2004/10/30* & $3^{*}$ & Liu (2006) \\
\hline & Xinghua Bay & Fujian, China & 119.48 & 25.52 & 136 & $2007 / 11 / 3$ & $2007 / 12 / 12$ & 39 & Jin et al. (2009) \\
\hline & Changhua County & Taiwan, China & 120.43 & 24.04 & 1 (tracked) & $2014 / 11 / 6^{*}$ & $2014 / 11 / 7^{*}$ & 1 & $\begin{array}{l}\text { Jung et al/ } \\
\text { (2018) }\end{array}$ \\
\hline \multirow{7}{*}{$\begin{array}{l}\text { Spring migra- } \\
\text { tion (Mar-April } \\
\text { or May) }\end{array}$} & Longtan Reservoir & $\begin{array}{l}\text { Liaoning, } \\
\text { China }\end{array}$ & 120.45 & 41.81 & $15^{*}$ & $1993 / 3 / 15^{*}$ & NA & NA & Qiu (2007a) \\
\hline & Yellow River Delta & $\begin{array}{l}\text { Shandong, } \\
\text { China }\end{array}$ & 119.04 & 37.82 & 5 & $2005 / 4 / 2$ & $2005 / 4 / 13$ & 11 & Shan et al. (2005) \\
\hline & Chongming Island & $\begin{array}{l}\text { Shanghai, } \\
\text { China }\end{array}$ & 121.95 & 31.52 & 61 & $2002 / 4 / 2$ & $2002 / 5 / 7$ & 35 & $\begin{array}{l}\text { Yuan and Zhang } \\
\text { (2006) }\end{array}$ \\
\hline & Chongming Island & $\begin{array}{l}\text { Shanghai, } \\
\text { China }\end{array}$ & 121.95 & 31.52 & $135^{*}$ & $2003 / 4 / 1$ & $2003 / 5 / 15$ & 44 & $\begin{array}{l}\text { Yuan and Zhang } \\
\text { (2006) }\end{array}$ \\
\hline & Min River Estuary & Fujian, China & 119.62 & 26.04 & 15 & 2003/5/9 & $2003 / 5 / 12^{*}$ & $3^{*}$ & Liu (2006) \\
\hline & Min River Estuary & Fujian, China & 119.62 & 26.04 & 12 & $2003 / 4 / 17$ & NA & NA & Liu (2005) \\
\hline & Xinghua Bay & Fujian, China & 119.48 & 25.52 & 226 & $2008 / 3 / 8$ & $2008 / 4 / 20$ & 43 & Jin et al. (2009) \\
\hline
\end{tabular}

*Indicates that the date and/or duration were estimated. Stopover sites with more than ten birds (0.25\% of the average wintering counts in 2016-2020) or used for more than seven days are shown in bold

also important. However, many habitats used by Blackfaced Spoonbills are close to developed areas, including major cities and harbors, and are experiencing severe habitat loss and human disturbance, especially on their wintering areas (Henmi and Takano 2012; Chen 2014; Choi et al. 2014; Wang et al. 2018). In addition, many of the internationally important sites for the Black-faced Spoonbill identified in this study currently lie outside of the existing WDPA or NNRs protection areas. Although some of sites could still be protected locally by provincial or state governments, this status might not provide adequate protection to the birds and their habitats against national development plans (Zhang et al. 2015). Therefore, we recommend that those sites qualifying as internationally important sites based on count data should be given national protection. Pickett et al. (2018) also suggested that the recent increase in population size was due to recent low numbers falling well below potential population carrying capacities of their habitat, but climate change and on-going habitat loss are predicted to have adverse impacts upon this species, causing ultimate reductions in the size of their global population before 2050. Thus, we would argue that the future of the Blackfaced Spoonbill is not totally secure, despite the recent increase in the global population.

To conclude, we urge continued field surveys and tracking studies to provide further information about the distribution and abundance of the Black-faced Spoonbill particularly in summering period and more tracking of adult individuals as the population increases. We also recommend the strengthening of protection and sympathetic management of wetlands along the China coast, based on the important sites identified in this study in Zhejiang and Fujian Province, as well as in the traditional wintering areas in Guangdong and Hainan Provinces. After identifying 


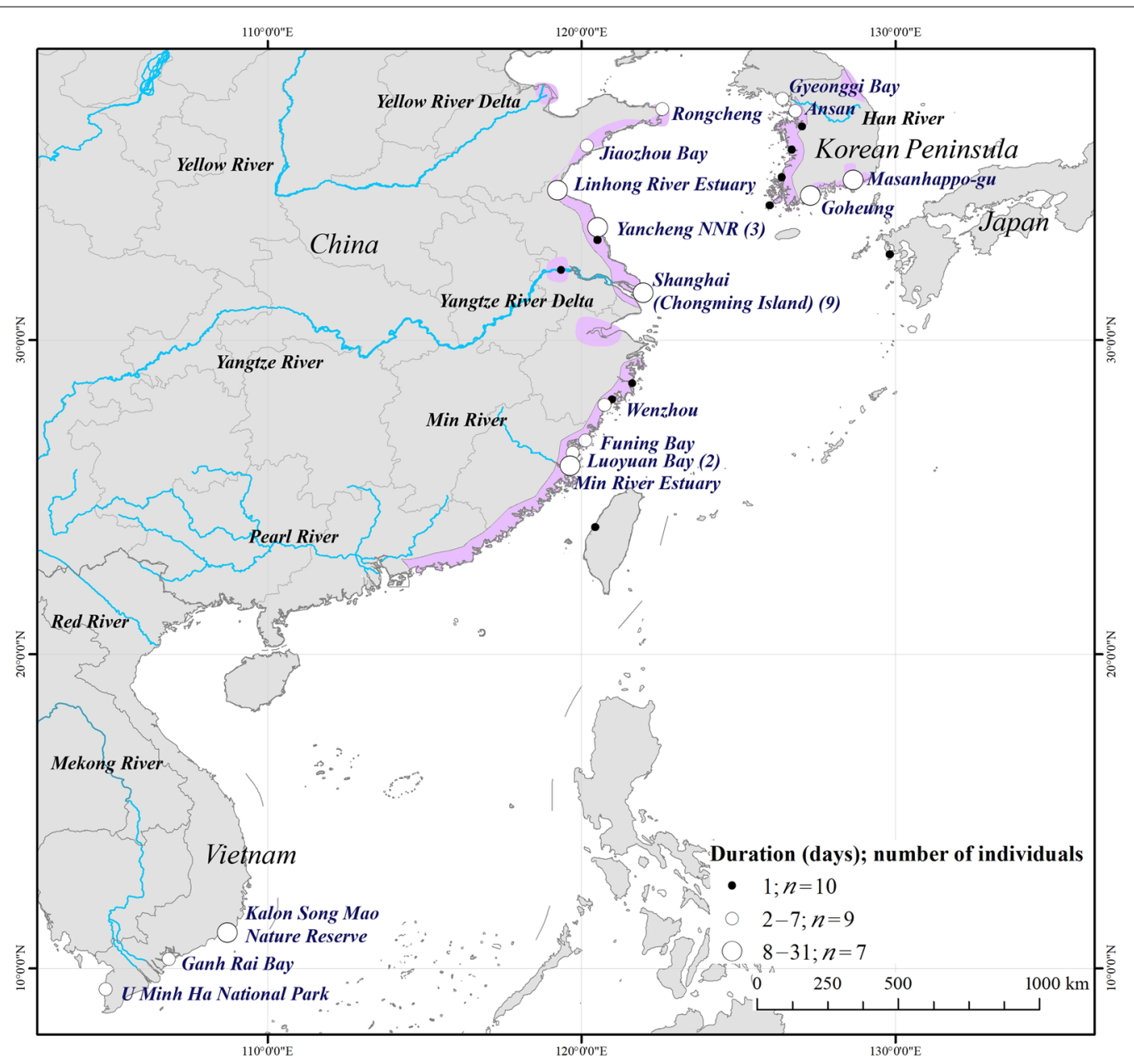

Fig. 7 The distribution of stopover sites of the 24 tracked Black-faced Spoonbills (Platalea minor) showing the longest stopover duration and the number of birds using the 26 sites during autumn migration. Numbers in brackets after site names indicate the number of different tagged birds recorded using that staging site. Among the sites, 10 sites were used for 1 day (black dots), 9 sites were used for 2-7 days (small white circles), and 7 sites were used for 8-31 days (large white circles). Sites used for at least 2 days were marked with their names on the map. Three sites were used more than once: Yancheng NNR in Jiangsu Province, 3 times; Shanghai (including Chongming Island), 9 times; Luoyuan Bay in Fujian Province, twice, all in China. Revised stopover range is shaded in light purple

key stopover sites along the southwest coast of Korea and east coast of China, regular monitoring activities should be established there to track the abundance and turnover rate of Black-faced Spoonbills during passage. Following this study, we also suggest the creation of an open platform to deposit count and census data, tracking studies results and regularly updated information on the distribution range and abundance of the Black-faced Spoonbill. This platform will be useful for the long-term scientific research, conservation planning and raising awareness of this iconic waterbird in East Asia. Through this participation process, we hope to engage more researchers and conservationists locally and globally joining hands to protect this species and their wetland habitats, which could also be beneficial for other waterbirds. 
Table 6 Number (and proportion) of all the tracked individuals using each of the wintering survey areas, compared to the numbers detected at each during the 2020 winter counts of Black-faced Spoonbill (Platalea minor)

\begin{tabular}{lllll}
\hline ID & Wintering site & $\begin{array}{l}\text { Number of tracked } \\
\text { birds }\end{array}$ & Corresponding survey area & $\begin{array}{l}\text { Number of } \\
\text { surveyed } \\
\text { population }\end{array}$ \\
\hline 1 & Japan & $2(8 \%)$ & Japan & $339(7 \%)$ \\
2 & Yangtze River Delta & $6(25 \%)$ & Jiangsu \& Zhejiang \& Shanghai & $196(4 \%)$ \\
3 & Fujian Coast & $3(13 \%)$ & Fujian & $338(7 \%)$ \\
4 & Pearl River Delta & $2(8 \%)$ & Hong Kong/Shenzhen \& Guangdong \& Macau & $726(16 \%)$ \\
5 & Taiwan & $5(21 \%)$ & Taiwan & $2783(61 \%)$ \\
6 & Other Coastal area & $0(0 \%)$ & Hainan \& Philippines \& Thailand \& Vietnam \& Korea & $173(4 \%)$ \\
7 & Inland China & $5(21 \%)$ & NA & NA \\
8 & Inland Southeast Asia & $1(4 \%)$ & NA & NA \\
\end{tabular}

The information on tracked birds was based upon data from 24 birds with complete autumn migration from the published literature (see "Methods" for details). The wintering counts were derived from field survey results in 2020 coordinated by the HKBWS

\section{Supplementary Information}

The online version contains supplementary material available at https://doi. org/10.1186/s40657-021-00307-z.

Additional file 1: Table S1. Sites used by Black-faced Spoonbills (Platalea minor) identified according to field survey data from published literature. Table S2. Parameters recorded for 34 individual Black-faced Spoonbills (Platalea minor) fitted with solar-powered satellite telemetry devices that completed at least one spring or autumn migration during 1999-2018 from published literature. Table S3. Sites used by Black-faced Spoonbills (Platalea minor) identified according to satellite tracking data from published literature. Table S4. Wintering counts of waterbirds in Poyang Lake, Wang Lake and Shijiu Lake during synchronized Yangtze waterbird surveys in 2004, 2005, 2016, 2018, 2019 and 2020.

\section{Acknowledgements}

We gratefully acknowledge the contribution of Hong Kong Bird Watching Society for the fieldwork and the tracking study teams for their contributions.

\section{Authors' contributions}

$L C, Y C, Y T Y$ and ADF conceived the ideas and designed methodology; YTY and $Y C$ collected the data; $Y C$ and $X D$ analysed the data. $Y C$ led the writing of the manuscript, with contributions from FM, YY and ADF. All authors contributed critically to the drafts. YC and YTY contributed equally to the manuscript. All authors read and approved the final manuscript.

\section{Funding}

The study was supported by the National Natural Science Foundation of China (Grant No. 31870369 and 31970433) and China Biodiversity Observation Networks (Sino BON).

\section{Availability of data and materials}

The data generated or analyzed during this study are included in this published article and its additional information files.

\section{Declarations}

\section{Ethical approval and consent to participate}

This study was examined and approved by the Animal Ethics Committee, Research for Eco-Environmental Sciences, Chinese Academy of Sciences, and was conducted under permission No. rcees-ddll-001.

\section{Consent for publication}

Not applicable.

\section{Competing interests}

The authors declare that they have no competing interests.

\section{Author details}

${ }^{1}$ School of Life Sciences, University of Science and Technology of China, Hefei 230026, China. ${ }^{2}$ State Key Laboratory of Urban and Regional Ecology, Research Center for Eco-Environmental Sciences, Chinese Academy of Sciences, Beijing 100085, China. ${ }^{3}$ Hong Kong Bird Watching Society, Hong Kong SAR, China. ${ }^{4}$ University of Chinese Academy of Sciences, Beijing 100049, China. ${ }^{5}$ Department of Bioscience, Aarhus University, Kalø, Grenåvej 14, 8410 Rønde, Denmark.

Received: 27 February 2021 Accepted: 28 November 2021

Published online: 17 December 2021

\section{References}

Baker RR. The significance of the Lesser Black-backed Gull to models of bird migration. Bird Study. 1980;27:41-50.

BirdLife International and Handbook of the Birds of the World. Platalea minor. The IUCN Red List of Threatened Species 2017: e.T22697568A119347801. 2017. https://doi.org/10.2305/IUCN.UK.20173.RLTS.T22697568A119347801.en. Accessed 29 January 2021.

BirdLife International and Handbook of the Birds of the World. Bird species distribution maps of the world. Version 2019.1. 2019. http://datazone. birdlife.org/species/requestdis. Accessed 29 January 2021.

Cao L, Zhang Y, Barter M, Lei GJBC. Anatidae in eastern China during the non-breeding season: geographical distributions and protection status. Biol Conserv. 2010;143:650-9.

Chen KN. Spatiotemporal dynamics of ecological variation affect an endangered migratory bird Black-faced Spoonbill (Platalea minor) in southwestern coast of Taiwan. Open J Ecol. 2014;4:87-97.

Choi CY, Nam HY, Lee WS. Behavioural responses of wintering black-faced spoonbills (Platalea minor) to disturbance. Wildlife Res. 2014;41:465-72.

Damba I, Fang L, Yi K, Zhang J, Batbayar N, You J, et al. Flyway structure, breeding, migration and wintering distributions of the globally threatened Swan Goose Anser cygnoides in East Asia. Wildfowl. 2020;6:97-123.

Ding C, Ding W, Yin Z, Sun Y, Xu Y. The breeding site and the conservation of the Black-faced Spoonbill in China. Orient Bird Club Bull. 2000;32:14-6.

Galvan I, Marchamalo J, Bakken V, Traverso JM. The origin of Lesser Blackbacked Gulls Larus fuscus wintering in central Iberia. Ringing Migration. 2003;21:209-14.

Henmi Y, Takano S. The influence of constructing a Shinkansen bridge on Black-faced Spoonbills Platalea minor wintering in Kyushu. Japan Ornithol Sci. 2012;11:21-8. 
Jansen FH. The migration of the sooty shearwater Puffinus griseus along the Netherlands coast. Limosa. 1981;54:117-26.

Jia R, Liu D, Lu J, Zhang G. Wetland destruction on migration routes threatens a breeding population of the endangered black-faced spoonbill (Platalea minor). Global Ecol Conserv. 2020;23:e01105.

Jin J, Liu B, Yu X, Lu C. Wintering and migration of Black-faced Spoonbill in Xinghua Bay, Fujian Province. Chin J Zool. 2009;44:47-53.

Jin W, Liu B, Wu C, Xu J, Zhuge G, Chen Y. A population survey of Black-faced Spoonbill in Zhejiang Province. In: The 7th symposium on biodiversity conservation in Zhejiang Province. 2017.

Jung SM, Kang JH, Kim IK, Lee HS, Lee SW, Oh HS. Autumn migration of Black-faced Spoonbill (Platalea minor) tracked by wild-tracker in East Asia. Korean J Environ Ecol. 2018;32:478-85.

Kang JH, Kim IK, Lee KS, Lee H, Rhim SJ. Distribution, breeding status, and conservation of the black-faced spoonbill (Platalea minor) in South Korea. For Sci Technol. 2016;12:162-6.

Kennerley PR. A review of the status and distribution of the Black-faced Spoonbill. In: Pickens V, editor. The Hong Kong bird report 1989:11625. Hong Kong: Hong Kong Bird Watching Society; 1990.

Kim IC, Kim SI. 2004 status of black-faced spoonbill Platalea minor in South Korea. In: Proceedings of 2005 international Black-faced Spoonbill symposium. 2005. p. 41-83.

Kokko H. Competition for early arrival in migratory birds. J Anim Ecol. 1999;68:940-50.

Kwon IK, Kang JH, Lee KS, Lee JY, Kim IK, Yoo JC. Breeding status and nest site characteristics of Black-faced Spoonbills Platalea minor on Chilsando Islands, Korea. Korean J Environ Ecol. 2015;29:703-9.

Kwon IK, Lee KS, Lee JY, Park JH, Yoo JC. Hybridization between the Blackfaced Spoonbill (Platalea minor) and Eurasian Spoonbill (Platalea leucorodia) in South Korea. Waterbirds. 2017;40:77-81.

Lee WS, Wee HH, Shin JR. Distribution characteristics of Black-faced Spoonbill Platalea minor in western coast of South Korea. J Ecol Environ. 2001;24:219-22.

Liu B. Black-faced Spoonbill and its habitat conservation in Fujian Province. Chin Wildlife. 2005;6:13-5.

Liu B. Distribution of Black-faced Spoonbill and its habitats in Fujian Province. Chin J Zool. 2006;4:48-52.

National Research Institute of Cultural Heritage (NRICH). Distribution map of natural monuments in 2007. Daejeon: National Research Institute of Cultural Heritage; 2007.

National Research Institute of Cultural Heritage (NRICH). Study on the habitat preservation of natural monument (Black-faced Spoonbill and Chinese Egret) III. Daejeon: National Research Institute of Cultural Heritage; 2014.

Pickett EJ, Chan M, Cheng W, Allcock J, Chan S, Hu J, et al. Cryptic and cumulative impacts on the wintering habitat of the endangered Blackfaced Spoonbill (Platalea minor) risk its long-term viability. Environ Conserv. 2018;45:147-54

Qiu Y. A new breeding site for Black-faced Spoonbill, an endangered wader, has been found again in Liaoning Province. Chin J Wildl. 2007a;28:55.

Qiu Y. Breeding, hibernation and migration of Platalea minor. J Liaoning for Sci Technol. 2007b;6:9-13.

Ramsar. The criteria for identifying wetlands of international importance. Ramsar Information Paper No.5. 2007.

Shan K, Xu J, Lu F, Song S, Xin H. Field survey on Black-Spoonbill and its habitat in Yellow River Delta National Nature Reserve. Sichuan J Zool. 2005;24:611-3.

Shibaev YV. Breeding of the Black-faced Spoonbill (Platalea minor) in Peter the Great Bay (Primorye, Russia). Situation and prospects. Ann Rep pro Natura Fund. 2010;19:151-64.

Son SJ, Kang JH, Lee SK, Kim IK, Yoo JC. Breeding and wintering home ranges of the Black-faced Spoonbill Platalea minor. J Asia-Pacific Biodivers. 2020;13:7-12.

Sullender BK, Barzen J, Silbernagel JJW. Foraging success and habitat selection of the Eurasian Spoonbill (Platalea leucorodia) at Poyang Lake. China Waterbirds. 2016:39:356-64.

Sung YH, Tse IWL, Yu YT. Population trends of the Black-faced Spoonbill Platalea minor: analysis of data from international synchronised censuses. Bird Conserv Int. 2018;28:157-67.
Takano S, Takeshita F, Henmi Y. Spatiotemporal utilization of feeding sites by the Black-faced Spoonbill Platalea minor in the Yatsushiro Sea, Japan. Ornithol Sci. 2014;13:59-66.

Tiunov I. Nesting of black-faced spoonbill (Platalea minor) (Pelecaniformes: Threskiornithidae) and hybrid partner on Khanka Lake (Russian Federation). J Asia-Pacific Biodivers. 2021;14:111-5.

Tiunov IM, Katin IO. Colonial nesting birds of Peter the Great Bay, sea of Japan (Pelecaniformes, Ciconiiformes). Russian J Marine Biol. 2020:46:405-11.

Ueta $\mathrm{M}$, Higuchi H. Difference in migration pattern between adult and immature birds using satellites. Auk. 2002;119:832-5.

Ueta M, Melville DS, Wang Y, Ozaki K, Kanai Y, Leader PJ, et al. Discovery of the breeding sites and migration routes of Black-faced Spoonbills Platalea minor. Ibis. 2002;144:340-3.

Wang XD, Kuang FL, Tan K, Ma ZJ. Population trends, threats, and conservation recommendations for waterbirds in China. Avian Res. 2018;9:14.

Wei GA, Lei FM, Yin ZH, Ding CQ, Ding WN. Nesting and disturbance of the Black-Faced Spoonbill in Liaoning Province, China. Waterbirds. 2005;28:420-5

Wetlands International. Waterbird population estimates. 2020. http://wpe. wetlands.org. Accessed 29 January 2021.

Wood C, Tomida H, Kim JH, Lee KS, Cho HJ, Nishida S, et al. New perspectives on habitat selection by the Black-faced Spoonbill Platalea minor based upon satellite telemetry. Bird Conserv Int. 2013;23:495-501.

Yeung CKL, Yao CT, Hsu YC, Wang JP, Li SH. Assessment of the historical population size of an endangered bird, the Black-faced Spoonbill (Platalea minor) by analysis of mitochondrial DNA diversity. Anim Conserv. 2006;9:1-10.

Yu YT. Longevity record of a colour-ringed Black-faced Spoonbill Platalea minor. Forktail. 2005;21:176-7.

Yu YT, Swennen C. Black-faced Spoonbill wintering in inland China. BirdingASIA. 2005;63.

Yu YT, Li CH, Tse IWL, Fong HHN. International Black-faced Spoonbill census 2020. Hong Kong: Black-faced Spoonbill Research Group, the Hong Kong Bird Watching Society; 2020.

Yu YT, Li CH, Tse IWL, Fong HHN. International Black-faced Spoonbill census 2021. Hong Kong: Black-faced Spoonbill Research Group, the Hong Kong Bird Watching Society; 2021.

Yuan X, Zhang K. Preliminary research of the migrant population of the Black-Faced Spoonbill Platatlea minor in Dongtan Wetland of Chongming Island, Shanghai. J East China Norm U (nat Sci). 2006;6:131-6.

Zhang F. Studies on the interspecies relationship of birds in the breeding sites of the Black-faced Spoonbill. J Mudanjiang Norm U (nat Sci). 2001;2:9-10.

Zhang M, Zou F, Cheong K, Chan S, Lei C. Human disturbance effect on Black-faced Spoonbill Platalea minor wintering in Macao. Chin J Zool. 2010;45:75-81.

Zhang M, Cheong K, Leong K, Zou F. Effect of traffic noise on Black-faced Spoonbills in the Taipa-Coloane Wetland Reserve. Macao Wildlife Res. 2012;39:603-10.

Zhang Y, Jia Q, Prins HHT, Cao L, de Boer WF. Effect of conservation efforts and ecological variables on waterbird population sizes in wetlands of the Yangtze River. Sci Rep. 2015:5:17136.

Zhao C, Zhang J, Wu Z, Wang X. Black-faced spoonbills were found in Rongcheng city, Shandong Province. Chin Wildlife. 2003;6:43.

Ready to submit your research? Choose BMC and benefit from:

- fast, convenient online submission

- thorough peer review by experienced researchers in your field

- rapid publication on acceptance

- support for research data, including large and complex data types

- gold Open Access which fosters wider collaboration and increased citations

- maximum visibility for your research: over 100M website views per year

At BMC, research is always in progress.

Learn more biomedcentral.com/submissions 